\title{
From Open Access to Open Science
}

More than a dozen years ago, in 2001, along with some tens of thousands of other researchers I once signed "An Open Letter to Scientific Publishers" in support of "the establishment of an online public library that would provide the full contents of the published record of research and scholarly discourse in medicine and the life sciences in a freely accessible, fully searchable, interlinked form" that led to establishment of the Public Library of Science (PLoS). Although open access journals had already existed to that date (e.g., BMC series), PLoS ONE, the first Open Access megajournal, celebrating this year its $10^{\text {th }}$ anniversary, strikingly marked a new era of Open Access journals, which were beginning to flourish. Starting from some 86 small journals in 1995, of which only 28 were still publishing more than 10 articles in 2001 (Crawford, 2002), the Open Access journal count in the World increased nearly 55 times by 2009, with the number of articles published each year increased by an order of magnitude only between 2000 and 2009 and reached ca. 200000 (Laakso et al., 2011). PLoS ONE itself was growing rapidly, and doubled the number of published articles from around 6 to 13 thousands (i.e. a thousand of papers published monthly) in 2010, when it received its first Impact Factor ( $=4.411$ according to Journal Citation Reports). This boost became possible in part due to the Internet, which enabled low-cost distribution of digital content, as well as disappearance of restrictions to the volume and the number of on-line articles in comparison to traditional printed journals.

All but three pioneer open access on-line journals that survived their first five years, had university affiliations, were sponsored by or affiliated with associations, one was affiliated with a commercial print publisher (Crawford, 2002), strongly suggesting that long lasting scholarly publishing is not possible without a kind of sponsorship or commerce as a source of support. Indeed, the last decade has seen a dramatic increase of the commercial Open Access journals. I do not think I am very wrong, if I say that almost all actively publishing scientists, at least in biomedical field, nowadays receives weekly from just one to dozens of invitations to submit a paper, or to have a discount if submission is made before a certain deadline, or to take a lead in editing a special issue in an open-access journal. In other words, a new Open Access business model in scientific publishing has grown, primarily relying on article processing charges (APCs) taken from the authors as a source of income (Laakso et al., 2011). This made a business competition to traditional subscription-based journals.

The early PLoS experiments in launching several high-aimed research journals, such as PLoS Biology, PLoS Medicine and others based on the "author-pays" model initially were severely criticized, e.g., by the Nature Publishing Group, for a presumed financial insolvency (Butler, 2003). Even more skepticism was added, when PLoS and BioMed Central both increased the APCs in 2006, and especially due to the launch of the PLoS ONE, intended to publish hundreds of papers, which was interpreted by some experts as an attempt to fill up PLoS's financial gaps (Butler, 2006). Surprisingly, however, not only the Open Access journals survived the tense years and flourished, but the Nature Publishing Group itself announced in January 2011 a new Open Access publication called Scientific Reports, which without doubt replicated the PLoS ONE model of low cost broad-scoped journal with a relatively high acceptance rate. Moreover, many journals have since implemented the so-called Hybrid Open Access, when the authors or their institutions agree to pay for the Open Access in an otherwise subscription-based journal. This implies that the new business model works well if not better than the traditional one. But in case of Hybrid Open Access, even a double price? 
Immediate access to the published research by colleagues around the globe is the main reason. As a result, - a considerable increase in download and citation metrics, i.e. immediate reach of the main goal of scientific publishing: share the knowledge with other researchers and receive a feedback. Decades ago someone would spend much time trying to rummaging for an important paper that is not accessible through institutional libraries and asked colleagues for help. Nowadays, with the overflow of the scientific literature it is often so that if the paper is not available to the researcher immediately or at least without a headache, it will be probably overlooked or ignored and hence not read and not cited. Therefore, the Open Access journals appear in a privileged position. This has become especially true due to search engines such as Google Scholar, which provides direct links to all pdf versions of an article available in the Web. On the other hand, growing monopolists of scientific periodicals with their high subscription rates far too often make scholarly articles inaccessible, especially for researchers from underfunded countries or institutions and affect them most severely. Instead of hitting a paywall each time, they turn to less legal ways of obtaining access to the published work, such as SciHub. Not surprisingly the publisher whose articles are most requested via Sci-Hub is Elsevier, perhaps, most difficult accessing in another way (Bohannon, 2016).

This is for sure not the whole story. Conventional subscription based printed journals with long lasting histories have strict limits of their volumes that do not allow processing the increasing number of submissions. A desperate fight for reputation and increase of the impact factors among them leads to a situation where a solid paper cannot find a place there, and either it passes many rounds of revisions until the reviewers are satisfied with the whole "story" (or not in the end!), or it travels from journal to journal rejected each time due to "lack of novelty", "not clear cut results", or just "not broad enough conclusions". The authors may be ready in the end, after several rounds of questions-andanswers and reformatting the manuscripts, to sell them for a "lower price", which may have a monetary equivalent along with a less rigorous review process. Perhaps, that explains at least some of the "manuscript flight" from a classical to new publishing paradigm. To a certain extent, Open Access journals, especially in their starting years, provide such an easier opportunity (note that the APC's are paid to the journal only if the manuscript is accepted); some of them take it as their policy. This was one of the points of critics of the early Open Access movement. Even now, the term "open access journal" is still sometimes perceived and interpreted as a "paid journal" in the first place, rather than really "open": if you have money, why not take a faster train? If you have no money, and your research is not outstanding, then both ways of publishing are less affordable and you are dragging behind others.

Gold Open Access defined as immediate or delayed access (open after a certain embargo time) to the published articles at a publisher/ journal web site is only a part of all Open Access bulk of scientific literature. Green Open Access takes another big part (Laakso et al., 2011). It means self-archiving, when the article is allocated at the author's personal web-page, or the author's institution web site, or institutional open repositories, in social networks like Academia, Research Gate and others, which often provide much friendlier interface than the original sites of many journals and allow quick reach of the targeted audience. Few researchers think twice before placing a PDF versions of their just published articles there, providing immediate Green Open Access; the vast majority of them do think they have the right to do that because they are the authors of the original research and because nearly nobody reads the Rights Transfer Agreements (RTAs, or other kind of Licenses) with the publishers (Poynder, 2017). However, self-archiving usually involve the research published in traditional subscriptionbased journals, thus immediately resulting in a collision with the RTAs the authors have signed themselves shortly before. So when it comes to self-archiving of the embargo articles, it more and more often leads to requests from the publishers for withdrawal of files placed in the web or even with actions at law. Does this help accessibility of the research? Certainly, it not.

The last but not least, all the studies of Open Access journals and their impact on science refer to journals published in English - a lingua franca of the modern science. Nevertheless, a huge body of scientific literature is still published in national languages; in some areas of biology up to $36 \%$ of the literature is published in languages other than English, e.g., Spanish, Chinese, and others (Amano et al., 2016). This makes another important barrier between the published research and the end users: the non-English documents cannot be understood fully without appropriate language skills, but what is more important - they cannot be searched using English keywords on Google Scholar and Web of Science even if they actually have English titles, or English abstracts, or both (Amano et al., 2016)! Imagine, if the majority of these journals were published in Open Access mode, it would still not have much sense since the real access to the results of research was lacking. Moreover, this further forms gaps and biases in our knowledge, as well as overrepresentation of positive results, as they are more likely to be published in high impact English-language 
journals (Egger et al., 1997; Amano et al., 2016).

Biological Communications belongs to a notable minority of Open Access journals in that it is an old university journal (previous title Vestnik of Saint Petersburg State University. Series 3. Biology.) issued for the first time in 1956, which starts making open access on-line version in parallel to printed version, which is also distributed now free of charge. Like almost all early open access journals of the period between 1993 and 1999 it is run by a group of scholars, it is published on a technically simple platform, as the Open Journal System is, and exploits a very simple "business model", which is "consisted of voluntary labor combined with a possibilities of using the editor's university web server free of cost" (Laakso et al., 2011) along with direct subsidies from Saint Petersburg State University. Although this is a simple and majorly technically outdated concept, it is an important step for the openness allowing journal's stable maintenance in spite of disclaimer both from subscriptionbased and "author-pays" models of Open Access. Instead, we allow authors to use freely the PDFs of their published work for self-archiving and advertising their research in professional networks, such as Research Gate or Academia in addition to the version published at our website (immediate Gold+Green OA). We totally switched this year from Russian to English and changed the title to break the last barrier between the journal and the readers. At least this gives us hope for achieving small to moderate success in the years to come, in particular the hope of dropping possible charges of not having a rigorous manuscript review process simply becasue the journal is independent of APCs. All this may serve further sustained development. How great it would be if other journals and publishers would join this model being subsidized directly from governmental bodies or funds, so that from the concept of Open Access we would move towards real Open Science where the results of scientific research, already costly for the society would be directly open and give faster feedback to the state, rather than help making business to individual monopolist corporations.

\author{
Yegor Malashichev, \\ Editor-in-Chief of "Biological Communications"
}

\title{
References
}

Amano, T., Gonzalez-Varo, J. P., and Sutherland, W. J. 2016. Languages are still a major barrier to global science. PLoS Biology 14 (12):e2000933. Bohannon, J. 2016. Who's downloading pirated papers? Everyone. Science 352 (6285):508-512.

Butler, D. 2003. Who will pay for open access? Nature 425:554-555.

Butler, D. 2006. Open-access journal hits rocky times. Nature 441:914.

Crawford, W. 2002. Free electronic referred journals: getting past the arc of enthusiasm. Learned Publishing 15 (2):117-123.

Egger, M., Zellweger-Zahner, T., Schneider, M., Junker, C., Lengeier, C., and Antes, G. 1997. Language bias in randomised controlled trials published in English and German. The Lancet 350 (9074):326-329.

Laakso, M., Welling, P., Bukvova, H., Nyman, L., Bjork, B.-C., and Hedlund, T. 2011. The development of Open Access journal publishing from 1993 to 2009. PLOS ONE 6 (6):e20961.

Poynder, R. 2017. Copyright: the immoveable barrier that open access advocates underestimated. In Open and Shut? Retrieved from http://poynder. blogspot.ru/2017/02/copyright-immoveable-barrier-that-open.html 